\title{
Individuo y sociedad en Th. W. Adorno: tensiones y mediaciones entre teoría de la sociedad y psicoanálisis
}

\author{
Individual and Society by Th. W. Adorno: Tensions and Mediations \\ between Social Theory and Psychoanalysis
}

José António Zamora Zaragoza ${ }^{1}$

\begin{abstract}
Resumen: Este artículo analiza la relación entre individuo y sociedad en Theodor W. Adorno. Para ello se centra en las tensiones y mediaciones entre teoría de la sociedad y psicoanálisis. Su punto de partida es el horizonte histórico concreto del vínculo que une a ambos: la conjunción de crisis e integración. Después presenta la constitución social de la subjetividad desde la perspectiva de teoría crítica, la economía psíquico-libidinal como matriz psicosocial de dicha constitución, la tesis de la debilitación del individuo en un capitalismo monopolista autoritario, su expresión en el carácter autoritario y el narcisismo herido, para acabar señalando los límites históricos del sujeto neurótico y modelo edípico y los elementos de una posible actualización de las aportaciones de una psicología social psicoanalítica.
\end{abstract}

Palabras clave: Th. W. Adorno, individuo, sociedad, teoría crítica, psicoanálisis, carácter autoritario, narcisismo herido.

Abstract: This article analyzes the relationship between individual and society in Theodor W. Adorno. For this, it focuses on the tensions and mediations between the theory of society and psychoanalysis. Its starting point is the concrete historical horizon of the link that unites both: the conjunction of crisis and integration. Then, it presents the social constitution of subjectivity from the perspective of critical theory, the psychic-libidinal economy as the psychosocial matrix of this constitution, the thesis of the debilitation of the individual in an authoritarian monopolistic capitalism and its expression in the authoritarian personality and the wounded narcissism. Finally, it presents the historical limits of the neurotic subject and oedipal model and the elements of a possible update of the contributions of a psychoanalytic social psychology.

Keywords: Th. W. Adorno, individual, society, critical theory, psychoanalysis, authoritarian personality, wounded narcissism.

Si no es a través de la psicología en la que continuamente se vuelven a interiorizar las coacciones objetivas no se podría entender ni que los seres humanos acepten pasivamente una situación de irracionalidad

\footnotetext{
${ }^{1}$ Doctor en Filosofía. Investigador Titular en el Instituto de Filosofía del CSIC (Madrid). Esta contribución se inserta en el Proyecto de I+D "Sufrimiento social y condición de víctima: dimensiones epistémicas, sociales, políticas y estéticas” (FFI2015-69733-P), financiado por el Programa Estatal de Fomento de la Investigación Científica y Técnica de Excelencia. E-mail: joseantonio.zamora@cchs.csic.es. Instituto de Filosofía, Consejo Superior de Investigaciones Científicas (IFS, CSIC), España.
} 
inalterablemente destructiva, ni que se integren en movimientos que contradicen sus intereses en una forma que salta a la vista.

Th. W. Adorno, Notas marginales sobre teoría y praxis.

Nada es infligido a la humanidad solo desde fuera.

Th. W. Adorno, Minima Moralia.

\section{Crisis e integración: el horizonte histórico del vínculo entre Teoría Crítica y Psicoanálisis}

Los retos a los que se enfrentaban aquellos pensadores críticos que pretendían interpretar el presente en el primer tercio del siglo XX desde la perspectiva abierta por la crítica de la economía política son bien conocidos. La historiografía de la Teoría Crítica o, como otros prefieren llamar, de la Escuela de Fráncfort, ha reconstruido y contextualizado con todo lujo de detalles esos retos teóricos y prácticos (JAY, 1973; DUBIEL, 1978; WIGGERSHAUS, 1988; ASBACH ,1997; DEMIROVIĆ, 1999). Quizás el término que mejor defina los retos de la Teoría Crítica sea el de "crisis", aunque más bien habría que hablar de una constelación de varias crisis. En primer lugar, la crisis económica de finales de los años 20. En segundo lugar, la crisis del movimiento obrero tras el fracaso de la revolución a escala mundial. Y, en tercer lugar, la crisis del marxismo, incapaz de dar una respuesta adecuada a las dos crisis mencionadas, convertido en una ciencia de legitimación del sistema soviético. Esa triple crisis sufriría una agudización adicional con la llegada al poder de Hitler y con el régimen nacional-socialista. La cuestión central a la que inicialmente había que dar respuesta era la del fracaso de las pretensiones emancipadoras.

$\mathrm{Si}$ atendemos a los factores movilizados por Marx para fundamentar la posibilidad de crítica y superación de la forma capitalista de socialización, podemos constatar la doble problematización a la que nos referíamos más arriba. Los protocolos de las discusiones sobre teoría del valor y de las crisis en el Instituto de Investigación Social en 1936 muestran una falta de acuerdo (HORKHEIMER, 1985, p. 405ss). Sin embargo, Horkheimer y Pollock compartían la valoración de la situación provocada por la llegada al poder del fascismo y por el New Deal en EEUU como el surgimiento de una nueva época definida por un capitalismo de Estado (POLLOCK 1933, 1941; HORKHEIMER, 1941). Las intervenciones del Estado autoritario o democrático estaban en condiciones de neutralizar los potenciales de las crisis económicas para hacer saltar el sistema. La 
1000 | Veritas | Porto Alegre, v. 63, n. 3, set.-dez. 2018, p. 998-1028

tendencia al establecimiento de una "economía planificada capitalista” y la debilidad de la clase trabajadora para resistirse a ese proceso destruían los supuestos vínculos entre crisis y praxis emancipadora. El capitalismo de Estado aparecía, pues, como una forma de sociedad que, sin eliminar el antagonismo de clases ni la apropiación privada del producto social, cancelaba las leyes económicas y las tendencias a las crisis del capitalismo liberal a través de la planificación estatal. La reproducción de esta forma de sociedad no parecía chocar ya con ningún límite económico inmanente.

Las dos posiciones encontradas, la de F. Pollock y la F. L. Neumann, coincidían en la constatación de una evolución del capitalismo hacia la monopolización, pero disentían sobre la cuestión de si esta tendencia había producido un vuelco hacia un capitalismo de Estado en el que la función reguladora del mercado estaba siendo sustituida por la intervención y regulación directas de la economía por parte del poder político, lo que podía suponer una estabilización del sistema económico, pese a sus contradicciones, de consecuencias terribles, como el Nacionalsocialismo ponía ante los ojos. Neumann afirmaba frente Pollock que el incremento de la función de la política que se manifestaba en el fascismo y que se prolongó en las democracias postfascistas era un producto del desarrollo del mismo capitalismo monopolista, es decir, de su tendencia a servirse de la burocracia estatal para realizar una planificación de la economía (cf. HORKHEIMER et al. 1981). Es probable que Horkheimer y Adorno (aunque este último no de manera tan decidida, cf. JOHANNES, 1995, p. 51ss.), al decantarse por la teoría de F. Pollock sobre el capitalismo de Estado, no fueran capaces de captar hasta qué punto la economía intervenida políticamente sigue estando sujeta a la ley de la acumulación y lejos de eliminar la competitividad y el mercado, resultan ser su reverso dialéctico. Sin embargo, su impresión, a la vista del Estado nacionalsocialista o estalinista y el New Deal norteamericano, de asistir a un proceso de consolidación de un capitalismo autoritario postliberal les ayudó, como veremos, a agudizar la mirada para los cambios cualitativos de la dominación moderna.

Otro de los elementos de la fundamentación marxiana de la crítica y de la praxis emancipadora que se tambaleaba tras la crisis del 29 es la tesis de la pauperización y sus efectos concienciadores y movilizadores en el proletariado. La expectativa formulada por Marx había quedado desmentida por el curso de los hechos, tal como constata Adorno hacia 
1942 en sus reflexiones sobre la teoría de las clases sociales, un texto que sólo se publicaría póstumamente:

\begin{abstract}
"Los proletarios tienen algo más que perder que sus cadenas. Su nivel de vida [...] no ha empeorado, sino mejorado. Con el desarrollo de las fuerzas técnicas de producción, a los trabajadores les ha correspondido menos tiempo de trabajo, mejor alimentación, vivienda y vestidos, protección de los miembros de la familia y de la propia vejez, una mayor esperanza de vida. Para nada se puede decir que el hambre les vaya a llevar necesariamente a una unión incondicional y a la revolución" (ADORNO, 1942a, 384).
\end{abstract}

A pesar de estas afirmaciones, Adorno no cae en el error de considerar esta nueva situación como una superación del antagonismo social o una desaparición objetiva de las clases. Más bien, al contrario, la concentración del capital hace crecer la diferencia de clases de modo objetivo y con ella la impotencia de amplias masas. Pero es esa misma impotencia la que permite al capital aparecer como expresión del conjunto de la sociedad y que este, en cuanto instancia anónima de toda la sociedad, sea visto como representación del equilibrio de intereses de todos sus miembros y a los grupos dominantes como sus representantes. Esto afecta de manera directa a la capacidad de los trabajadores y trabajadoras para una autorreflexión crítica de su propia praxis alienada y cosificada. Es decir, afecta a una de las condiciones fundamentales de la crítica del capitalismo y de la praxis emancipadora en la perspectiva de Marx.

Desde que Horkheimer asumió la dirección del Instituto de Investigación Social en Frankfurt, el psicoanálisis se convierte en uno de los principales instrumentos de la renovación teórica exigida por el "fracaso" de la revolución en occidente. En el marco del programa de Materialismo Interdisciplinar en que se concreta dicha renovación adquieren especial relevancia los análisis psicológicos, que en la nueva situación han de contribuir a explicar la lealtad bastante generalizada de los dominados a pesar de la agudización manifiesta de las contradicciones económicas. Esta lealtad sólo es comprensible si "la acción de estratos numéricamente significativos no está determinada por el conocimiento, sino por un engranaje pulsional que falsea la conciencia" (HORKHEIMER, 1932, p. 59). La génesis de una conciencia de clase capaz de conocer y desentrañar la realidad contradictoria y las formas de dominación existentes está bloqueada e impedida por poderes irracionales y coactivos 
que consiguen mantener latentes los conflictos a los que empujan las mencionadas contradicciones.

El psicoanálisis se convierte así en la fuente principal de una psicología social cuya tarea debía consistir en palabras de E. Fromm - una figura clave de la primera etapa de la Teoría Crítica- en "comprender la estructura pulsional y la actitud libidinal de un grupo, en gran medida inconsciente, a partir de la estructura socio-económica" (FROMM, 1932, p. 42). La violencia externa de los aparatos de poder o las construcciones ideológicas de la sociedad burguesa ya no bastaban para explicar la conformidad social de los sujetos oprimidos y dominados, resultaba necesario analizar las estructuras de carácter que favorecen la conformidad con el sistema. Para ello era preciso tener en cuenta que dichas estructuras se consolidan en el curso de la maduración individual a partir de disposiciones del comportamiento en el marco del desarrollo libidinal según las fases oral, anal y fálica establecidas por Freud. Estaba a la vista que la adaptación de la libido a la estructura económica a través de los mecanismos de represión y sublimación analizados por el psicoanálisis posee un efecto estabilizador. La racionalización funcional de los impulsos inconscientes contribuye a enmascarar las contradicciones sociales y a mantener las estructuras sociales de dominación (cf. SCHMID NOERR, 2001).

Por tanto, el curso de la historia imponía la necesidad de recurrir al psicoanálisis como "ciencia auxiliar" de la teoría social (HORKHEIMER, 1932, p. 57). Sin su contribución resultaba imposible responder a la pregunta de por qué los individuos en una situación revolucionaria, en vez de llevar a cabo una acción liberadora, abrían a sus verdugos el camino al poder. Esta cuestión clave no se podía afrontar sin una colaboración de la crítica de la economía política con la teoría de la cultura y con el psicoanálisis, por más que la relación entre teoría social y psicoanálisis fuera de tensión y no de unificación, y de que el primado en esta relación siguiera correspondiendo a "la teoría objetiva de la sociedad" (ADORNO 1969, p. 182, cf. MAISO 2013; DAHMER 1994, p. 85). Este desplazamiento en el concepto de sociedad constituye uno de los rasgos distintivos de la Teoría Crítica. No es que la crítica de las ideologías en sentido clásico se dejara completamente de lado. Las reflexiones sobre ciencia y pensamiento burgués durante los años 1930, llevadas a cabo por M. Horkheimer y que culminan en el famoso artículo sobre "Teoría 
tradicional y teoría crítica” de 1937, prolongan en cierto sentido la crítica de las ideologías en la estela de Marx (MEYER 2005, p. 65ss). Pero el concepto de ideología como "conciencia necesariamente falsa" resultaba claramente insuficiente y exigía incorporar en la explicación de los nuevos fenómenos históricos la economía psíquico-libidinal de los individuos y la producción de la cultura. Si en la socialización capitalista, la mediación objetiva de unas relaciones sociales cosificadas y autonomizadas frente a los sujetos que las producen, está en el origen de las mistificaciones, de la naturalización del orden capitalista, de que los individuos queden atrapados por la apariencia de la esfera de la circulación, parece necesario a la luz de los acontecimientos históricos explicar a través de qué procesos y mecanismos se impide a los individuos romper el hechizo de esa apariencia, puesto que los elementos objetivos y subjetivos identificados por Marx como detonantes del proceso de autorreflexión crítica y de praxis liberadora no se habían mostrado efectivos. La contribución de Freud es tan fundamental porque muestra los mecanismos psicológicos que puede ayudar a entender por qué la sociedad burguesa, a pesar de todos los antagonismos y de su creciente agudización, ha podido seguir reproduciéndose.

Pero la clave para entender la dialéctica individuo-sociedad no es el psicoanálisis, sino la crítica de la economía política de Marx actualizada (cf. KÜPPER, 2009).

\section{Individuo y sociedad: constitución social de la subjetividad}

Una teoría de la sociedad que pretenda ir más allá del mero diagnóstico social debe confrontarse con el problema de la constitución de las relaciones sociales dentro de un modo de producción en el que confluyen un determinado desarrollo de las fuerzas productivas, una forma de apropiación del excedente de producción o un régimen de dominación social concreto y una cultura específica, así con atender a la dinámica que rige las transformaciones de dichas relaciones en el tiempo. Lo decisivo en el capitalismo es la producción de la mercancía "fuerza de trabajo" y la conformación de las relaciones sociales bajo la forma del capital, de la que es parte constitutiva la apropiación particular del beneficio (ADORNO, 1968, p. 354). 
Existen enormes dificultades para hablar de la "sociedad" en una época de nominalismo sociológico y de proliferación de "diagnósticos sociales" (sociedad del riesgo, sociedad del cansancio, sociedad del conocimiento, sociedad de las sensaciones, etc.). Aunque dichos diagnósticos se basen en generalizaciones de fenómenos particulares elevados a caracterizaciones universales, cualquier discurso sobre la sociedad está bajo sospecha de ontologización inapropiada. La virtualidad del concepto de "abstracción real" (Hegel/Marx), al que recurre la Teoría Crítica, consiste precisamente en evitar una ontología social y en permitir al mismo tiempo el planteamiento de cuestiones fundamentales que escapan al nominalismo. Entre ellas está la cuestión de la síntesis social, es decir, la pregunta por aquello que mantiene unida a la sociedad: en el capitalismo la persecución de los intereses privados individuales y la autonomización de las relaciones sociales cosificadas no están contrapuestos, sino que se exigen mutuamente. También la cuestión de la dinámica social, es decir, de si existe algo así como proceso general (líneas evolutivas, crisis sistémicas, etc.), sin por ello incurrir en una teleología histórica o una metafísica del proceso histórico. Y, finalmente, la cuestión de la praxis, es decir, de la mediación que existe entre las acciones de individuos y grupos y las estructuras sociales que son resultado de ellas, pero se convierten en su marco y límite. En definitiva, la cuestión de la síntesis social permite enfrentarse a un conjunto de problemas esenciales, a su configuración histórica específica y a los conflictos y respuesta sociales que los definen: la reproducción material de la vida (producción y trabajo), la reproducción sexual (relación de los sexos y las generaciones), la reproducción cultural (conciencia, ideología, simbolizaciones).

En este sentido, la Teoría Crítica debe ser entendida como un intento de actualización del marxismo, pero no como un corpus dogmático, cerrado y acabado, sino como un instrumental conceptual que permite analizar las cuestiones y problemas señalados hasta aquí. Una de las cuestiones más controvertidas al respecto es si la actualización realizada especialmente por Th. W. Adorno conduce a un modelo de subsunción de la subjetividad a expensas del modelo de emancipación (suspensión de la praxis, minimización del conflicto de clases, pesimismo histórico, etc.). Algunas de sus afirmaciones parecen corroborar esta interpretación: 
El proceso de autonomización del individuo, función de la sociedad de intercambio, culmina en su eliminación por medio de la integración. (ADORNO, 1966a, p. 259).

Triunfo de la integración, los seres humanos están identificados hasta en sus más íntimas formas de comportamiento con lo que les ocurre. (ADORNO, 1965, p. 18).

Sin embargo, si tenemos en cuenta el conjunto de su obra, Th. W. Adorno elabora un complejo modelo de mediación dialéctica entre subsunción y emancipación que, en la forma como se articula, posee un índice histórico innegable (revisable), pero contiene una riqueza de matizaciones que no siempre se tiene en cuenta y solo desde ella es posible precisar la relación entre lo universal y lo singular, la identidad y lo noidéntico, el individuo y la sociedad. Ningún término de la relación puede tomarse como punto de apoyo fijo o fijado al margen de la mediación, lo cual no quiere decir que se ontologice o se positivice dicha mediación. El concepto de mediación en Th. W. Adorno trata de atender al poder de la objetividad, de la universalidad social abstracta, desvelar su carácter coactivo, su pretensión totalizadora y, al mismo tiempo, señalar su fracaso último, la imposibilidad de alcanzar una identidad lograda mientras exista la coacción. Desmentir, por tanto, su naturalización o su insuperabilidad. El éxito de una completa identidad coactiva es la completa aniquilación de los individuos: Auschwitz. Solo ahí se cumple el principio de identidad acabada en su negatividad aniquiladora. Pero también solo desde ahí se entiende el telos al que apunta dicho principio que informa la síntesis social llevada a cabo por capital. Esto quiere decir que no existe singularidad fuera o al margen de la mediación, pero la singularidad no desaparece completamente en ella. La coacción instaura permanentemente una distancia, genera un resto no completamente integrable. La figura de una "dialéctica negativa" es inseparable de esta determinación no afirmativa de la categoría mediación que lleva a cabo Th. W. Adorno.

Dicha mediación supone, en primer lugar, inversión. La autoconservación de todos y cada uno de los individuos está mediada por el conjunto de la sociedad. Pero la forma en que la sociedad está organizada, supuestamente orientada a garantizar la autoconservación de sus miembros, genera y reproduce relaciones de dominación de unos individuos sobre otros que no pueden ser atribuidas sin más a la necesaria 
división del trabajo. La finalidad última de la organización social, es decir, garantizar que las necesidades de sus miembros encuentren satisfacción y quede eliminado el sufrimiento evitable (ADORNO, 1966a, p. 203.), se ve frustrada a causa de las relaciones de dominación que producen una inversión en la relación entre la autoconservación de todos los individuos y la organización social. Ésta ya no es un medio para alcanzar aquella, sino que la propia autoconservación mediada por las relaciones sociales de dominación, fundamentalmente económica, se convierte en un medio de la producción y acumulación de beneficios (ADORNO, 1968, p. 361). Paradójicamente, de esta manera, los individuos quedan reducidos a mera lucha por la autoconservación $\mathrm{y}$, de este modo, se ve frustrada la autonomía que les permitiría perseguir finalidades más allá de ella, posibles sólo cuando la organización social realmente persigue la autoconservación de todos sus miembros convertida en su finalidad efectiva.

Esta inversión (ADORNO, 1963, p. 274) es la que, como viera Marx, se expresa en el concepto de "capital", sujeto desubjetivado del proceso social. El proceso social es dirigido por una especie de mecanismo, la reproducción ampliada del capital, que arrastra consigo a los individuos reducidos a meros productores o consumidores. Para Adorno no cabe duda de que la objetividad social en cuanto totalidad antagonista constituye una unidad real que a todos abarca. La inversión que la constituye significa sobre todo hipostatización, cosificación autonomizada frente a los individuos. La forma de reproducción del capital es verdaderamente un mundo invertido en el sentido de que, a través de las acciones que aseguran su reproducción y en ellas, se independiza respecto a los individuos que las ejercen, desarrolla una dinámica propia conforme a leyes que funcionan, por así decirlo, a sus espaldas. Esto lo afirman tanto Marx como Adorno no sin ironía, pues su concepto de sociedad pretende ante todo realizar una crítica de esta autonomización de la síntesis social, que es al mismo tiempo construcción ideológica y expresión de la forma específica de desarrollo económico capitalista.

Este doble carácter procede del hecho de que los individuos son sujetos y objetos al mismo tiempo. El sistema se constituye gracias a sus acciones, es su resultado, su "naturalidad" es "pseudo-naturalidad" (Naturwüchsigkeit), pero como tal aparece enfrentado a ellos siguiendo una dinámica que les arroya y les convierte en meros ejecutores y 
apéndices de la objetividad que han producido (ADORNO, 1969b, p. 316). La objetividad social autonomizada aparece pues como algo externo y contrapuesto, cuya génesis se ha vuelto opaca, casi impenetrable para unos individuos que no son capaces de desentrañar el proceso de dicha autonomización, por más que la abstracción real de la suma de valores de cambio no es otra cosa que la cosificación independizada del conjunto de su trabajo. Mientras siga vigente la objetividad social autonomizada frente a los individuos, su libertad se verá reducida a plegarse a las leyes del mercado, si no quieren ser penalizados con la ruina económica o la marginalidad social. Esto significa reproducir en la propia acción la inversión en que consiste el capital, es decir, no perseguir la satisfacción de las necesidades como la finalidad de su acción económica, sino convertir dicha satisfacción en instrumento de una acción económica orientada a la maximización del beneficio.

Así pues, la subjetividad autónoma, el principio de individuación moderno, no es sin más aquello que se opone por sí misma a la heteronomía, al dominio del universal social sobre los individuos singulares. En cuanto algo "derivado" (ADORNO, 1966b, p. 91), debe "su cristalización a las formas de la economía política” (ADORNO, 1951a, p. 169). Como señala Th. W. Adorno en muchos de sus textos, cuanto más se afirma ciegamente esa individualidad, cuanto más juramentada está con la propia autoconservación a través del antagonismo social, tanto más sucumbe el sujeto a la mediación social de unas relaciones determinadas por los principios de intercambio y de dominación de la naturaleza exterior e interior. La crítica de la dominación social no puede realizarse en nombre de una subjetividad constitutiva, pues dicha subjetividad, en la afirmación irreflexiva de sí misma y en la desconsideración de las mediaciones sociales que la constituyen, afirma y confirma la síntesis social que la produce y la destruye al mismo tiempo.

Por eso, la Teoría Crítica ha puesto buena parte de su empeño teórico en desentrañar los vínculos entre los procesos de subjetivación y su resultado -que de ninguna manera se puede considerar un resultado logrado- con la configuración de las relaciones sociales en la sociedad burguesa capitalista. El principio proto-burgués de la afirmación de la subjetividad autónoma es un principio derivado, cuya génesis es preciso sacar a la luz, en primer lugar, para entender por qué la promesa de emancipación moderna ha fracasado y, en segundo lugar, para intentar 
abrir a los individuos aquellas posibilidades de libertad y singularidad que la totalidad social antagónica bloquea.

La subjetivación es un proceso presidido por la cosificación social objetiva que genera la ilusión socialmente necesaria de una autonomía, sin la que no puede funcionar la esfera de la circulación. Pero en realidad esta autopercepción como subjetividad constitutiva supone una pérdida de realidad, una pobreza de experiencia. Del mismo modo que el orden social capitalista oculta su génesis histórica y el carácter social de las relaciones autonomizadas y cosificadas frente a los individuos, la subjetividad constitutiva olvida y desconoce las condiciones sociales de su constitución y el carácter cosificador de su relación con el mundo, con los otros y consigo misma, que es resultado de la cosificación de esas condiciones sociales. Pensar y actuar bajo la mediación del capital, esto es, de la universalidad social abstracta, solo es posible si el primado y la precedencia de esa universalidad permanecen inconscientes.

\section{Matriz psicosocial: economía psíquico-libidinal}

Aunque en el capitalismo resulta decisiva la autonomización de las relaciones sociales en estructuras emancipadas respecto a sus portadores individuales, que, si bien se reproducen a través de ellos, lo hacen por encima de sus cabezas (cf. CLAUSSEN, 1995, p. 37), sin embargo, esto no anula que la contradicción social de carácter procesual medie de manera universal todo lo individual y por tanto que posea una doble cara psicológica-individual y sociológica. La interiorización de la dominación social cristaliza en el individuo a través de los conflictos psíquicolibidinales. Y esos conflictos son constitutivos del doble carácter del yo, dependiente de las exigencias externas e internas y relativamente independiente frente a ellas. Th. W. Adorno sostiene que es posible reconocer en esos conflictos psíquico-libidinales la mediación del antagonismo social y que, por lo tanto, son una fuente de conocimiento imprescindible sobre el antagonismo social mismo (ADORNO, p. 1955, p. $50)^{2}$.

\footnotetext{
${ }^{2}$ A esta posibilidad de vincular psicoanálisis y teoría crítica no le han faltado críticas más o menos justificadas. Cf. REICHE, 2004; SCHNEIDER, 2011. Para un juicio más ponderado que no oculta las tensiones, contradicción, unilateralidades e imprecisiones de la lectura adorniana de Freud, cf. SCHILLER, 2017, p. 214-270.
} 
La aportación del psicoanálisis es tan importante porque ofrece una triple descripción de los fenómenos psíquicos: tiene en cuenta la economía de energías y estímulos bajo el principio de placer-displacer, la tópica de ello, yo y superyó y la dinámica de los persistentes conflictos pulsionales (FREUD, 1925, p. 85; cf. KIRCHHOFF, 2010). La necesidad vital y la menesterosidad del recién nacido lo remiten para su supervivencia al entorno y las personas que puedan reconocer las necesidades que reclaman una satisfacción y la eliminación de la tensión que generan. De este modo se pone en marcha el proceso de individuación que posee un carácter conflictivo entre deseo/necesidad y respuesta/desamparo, entre fantasía y realidad, entre recuerdo del objeto y presencia real. El propio aparato psíquico se va formando en este proceso de carácter conflictivo y está marcado en su constitución por él. La superación de un esquema de acciones reflejas y satisfacciones inmediatas del deseo gracias a la inhibición o la postergación de la satisfacción es la condición del pensar, del soñar, de la escisión entre consciente e inconsciente, de la represión y la aparición de síntomas, etc. Esto es, la condición de la individuación y de la cultura. Así pues, el conflicto deseo-realidad resulta constitutivo de lo psíquico, que de este modo queda anclado permanentemente al cuerpo, sin que lo corporal pueda ser reificado en cuanto naturaleza anterior y externa a la mediación social. Tampoco el análisis da acceso directo a un sustrato natural que se pueda fijar al modo positivista; tan solo permite rescatarlo mediante la reconstrucción del proceso de individuación gracias su traducción y reelaboración (KIRCHHOFF, 2009). Las necesidades no son una realidad primera y no mediada (ADORNO, 1942c, p. 392).

En todo caso, el sujeto y la cultura se desarrollan, según Freud, a expensas de la satisfacción del instinto.

\footnotetext{
Creemos que la cultura se ha creado bajo el impuso de la necesidad vital a expensas de la satisfacción de la libido, y en gran medida es recreada continuamente en tanto que el individuo que entra a formar parte de la comunidad humana vuelve a repetir el sacrificio de la satisfacción de la libido en beneficio de la totalidad (Freud 1916-17, 15s).
}

La necesidad vital anuda a los individuos a la totalidad social (ADORNO, 1952, p. 35), de la que dependen para asegurar su supervivencia, pero que perpetúa sus sufrimientos y les impone innumerables renuncias. La interiorización de las normas y de las 
prohibiciones sociales cristaliza en la instancia del superyó, por la que la sociedad se extiende al ámbito psíquico y pulsional. En su vinculación con el yo organiza los mecanismos de defensa y la represión, a través de los que se sustancia la mediación entre los impulsos del ello, los mandatos del superyó y las exigencias de la realidad. "El concepto de yo es dialéctico, psíquico y no-psíquico, una porción libido y el representante del mundo" (ADORNO, 1955, p. 70). La realización por parte del yo de esa mediación a tres bandas demanda una capacidad de distanciamiento racional frente a la triple exigencia y dependencia, es decir, una capacidad de reflexión sobre esas exigencias y de autorreflexión sobre las condiciones de la propia constitución. Pero dicha capacidad es siempre precaria, el sujeto no es dueño en su propia casa y se ve acosado desde dentro y desde fuera y obligado permanentemente a frágiles compromisos, amenazado continuamente de fracaso, marcado por las cicatrices de fracasos efectivos.

Una diferencia fundamental entre Freud y Adorno es que el primero atribuye al conflicto entre deseo y realidad un carácter que podríamos considerar antropológico y considera las renuncias impuestas por la sociedad la condición necesaria para una individuación aceptable, inalcanzable sin ellas. El desplazamiento del cumplimiento es no solo racional, sino la condición del avance y de la posibilidad de perfeccionamiento de la propia satisfacción del deseo. El aprendizaje es duro, pero necesario e inevitable. Por el contrario, en Adorno el concepto de necesidad vital posee un claro índice histórico y social, no proviene de la "naturaleza" en sentido genérico, sino del "segunda naturaleza". Y esto permite desvelar el vínculo entre exigencias sociales de adaptación e irracionalidad (KIRCHHOFF, 2014, p. 54). El carácter coactivo de la necesidad vital, incluso el que proviene del hambre (ADORNO, 1969b, p. 347), está determinado por las relaciones sociales. Por tanto, su coacción y las renuncias que impone no pueden ser reificadas y naturalizadas. La autoconservación por medio de la adaptación a exigencias que no se pueden justificar racionalmente imponen una introyección del sacrificio que destruye la sustancia de lo que se quiere conservar (ADORNO, 1951a, p. 263). Ciertamente, la búsqueda de placer choca con la necesidad vital que proviene de la exigencia de supervivencia. Pero dicha necesidad introduce lo social "hasta en las más íntimas células psicológicas" (ADORNO, 1966b, p. 88). Aplazamiento y desplazamiento constituyen proto-fenómenos de la renuncia social e históricamente impuesta 
(ADORNO, 2001, p. 111). Los sacrificios que se exigen del sujeto bajo formas sociales determinadas por la dominación y el antagonismo siempre suponen un exceso, un plus innecesario de autonegación, de renuncia, de frustración, que viene determinado por esa configuración de las relaciones sociales.

Para poder afirmarse en la realidad, el yo tiene que reconocerla y actuar conscientemente. Pero, para que el individuo pueda cumplir las renuncias que le son impuestas y a menudo carecen de sentido, tiene que erigir prohibiciones inconscientes y mantenerse él mismo en gran medida en el inconsciente. [...] El esfuerzo cognitivo realizado por el yo para lograr de la autoconservación, tiene que suspenderlo simultáneamente una y otra vez y negarse a sí mismo la autoconciencia. La contradicción conceptual que puede demostrarse de manera tan elegante contra Freud, no es culpa de la falta de pulcritud lógica, sino de la necesidad vital. (ADORNO, 1955, p. 71).

El exceso de renuncia que se impone como necesidad vital proviene de una sociedad antagonista y, por tanto, la necesidad de adaptación posee un carácter irracional. Lo que el psicoanálisis desvela, la irracionalidad del comportamiento racional, es reflejo de una irracionalidad objetiva (ADORNO, 1952, 40).

Si tomamos en serio la determinación histórica y social de la economía psíquico-libidinal, el crecimiento de los antagonismos sociales pone al descubierto el núcleo temporal del psicoanálisis (ADORNO, 1955, p. 83). En este sentido, la tesis sobre el debilitamiento del individuo es clave para comprender la perpetuación de un sistema que produce sufrimientos injustificables, pues pretende dar cuenta de las nuevas condiciones históricas y sociales en las que el yo tienen que gestionar el precario equilibrio que define su función integradora entre las exigencias exteriores y los impulsos internos. El yo debilitado cada vez está menos en condiciones de llevar a cabo su función de instancia mediadora entre la realidad social con sus imperativos y los impulsos libidinales. Ni siquiera en las formas precarias e inestables que se encarga de desentrañar y estabilizar el psicoanálisis.

\section{Debilitación/aniquilación del individuo}

La progresiva subsunción del universo cultural y de las dinámicas psíquicas bajo las lógicas sistémicas y las estructuras organizativas 
capitalistas que acompaña la evolución del capitalismo suponía una transformación de dimensiones desconocidas hasta entonces. Los pensadores de la Teoría Crítica se enfrentaban a una capacidad reforzada de integración que debía ser explicada. La deshumanización se había vuelto inmanente al sistema, que ya no necesitaba excluir a nadie de la $>$ cultura $=$ porque esta se había convertido en el instrumento con el que todos quedan incluidos. La ideología, en el sentido de una mediación entre autonomía y dominación, ya no era necesaria, porque ya no había nada que temer de la autonomía: "La inmediatez coactiva impide a los seres humanos reconocer justo el mecanismo que los mutila: éste se reproduce en su conciencia sumisa" (ADORNO, 1942b, p. 227). Estamos, pues, ante una doble tesis que será fundamental. Por un lado, la debilidad objetiva de los individuos en un capitalismo monopolista les impide reconocer el mecanismo que produce esa misma debilidad. Por otro lado, ese mecanismo se reproduce en la conciencia cimentando la identificación con un orden de dominación injusto. De qué manera tiene lugar esta reproducción en la conciencia, es decir, cómo se traducen las relaciones sociales bajo las condiciones de un capitalismo avanzado en la subjetivación de los individuos, esto merece una explicación.

La >debilidad del yo= expresa según Adorno una configuración psíquica que se corresponde con la liquidación tendencial del "individuo" (burgués o proletario) en el capitalismo monopolista. El yo no sólo se constituye a través de los conflictos entre los impulsos libidinales y los procesos sociales de represión, sino que también confluyen en él las tensiones de la realidad social antagonista. Esto hace que los intentos de ajuste entre las tendencias internas y las exigencias sociales se produzcan siempre en constelaciones conflictivas y estén enredados en contradicciones. El interés por la autonomía y la posibilidad de afirmación de sí mismo se encuentra en conflicto con las exigencias sociales de adaptación, que es el precio para asegurar la autoconservación. Si no quiere ser expulsado del engranaje social, el individuo tiene que acatar las reglas de juego que dicta la situación dominante, pero las exigencias que se derivan de este acatamiento van asociadas a renuncias que no son razonables a primera vista. Ante esto caben dos posibilidades: enfrentarse de modo consciente a la represión social poniendo en peligro la autoconservación o poner en marcha maniobras de suavización y 
pacificación que impidan tener que soportar grandes mermas de la autoestima. Esta segunda forma es, de hecho, la predominante.

En el capitalismo monopolista las exigencias provenientes del exterior se han vuelto tan masivas y el individuo tan débil frente a ellas, que las renuncias que le imponen no pueden ser internalizadas y convertidas en elementos de la propia conciencia, pero tampoco puede el yo identificarse con ellas. Dominado por el temor más o menos consciente tanto a los reveses sociales como a las privaciones psíquicas, termina renunciando a toda protesta contra las exigencias sociales en muchos casos carentes de sentido. "Si en otro tiempo las ideologías actuaban como cemento de unión, éste se ha deslizado hacia la prepotente situación existente en cuanto tal, por un lado, y hacia la constitución psicológica de los seres humanos, por otro" (ADORNO, 1965, p. 18). Debido a esta polarización, la adaptación ya no está mediada por la constitución de una instancia propia, que, si bien interioriza las pretensiones provenientes de la sociedad, también permite un distanciamiento reflexivo frente a las mismas. Por eso la adaptación que realiza el yo permanece externa a él y queda quebrada su resistencia frente a dichas exigencias.

Las condiciones sociales e históricas alteran el acceso del yo a la satisfacción de los impulsos, a una sublimación no represiva, a una fortaleza del yo sin acorazamiento bajo el principio de la autoconservación y a una socialización solidaria sin represión adicional. En este sentido es en que la situación de los individuos en el capitalismo monopolista, situación responsable de un especial debilitamiento de los seres humanos y de su subjetividad, produce nuevas formas agudizadas de empobrecimiento y regresión psicosociales. Aquellas condiciones que confieren fuerza al individuo frente a la sociedad han sido prácticamente eliminadas. Las formas mediadas de subjetividad, de capacidad de experiencia y disfrute, el alcance de la sublimación y la necesidad de ella, etc. son sustituidas cada vez más por la intervención directa de la sociedad en la economía pulsional de los seres humanos (cf. MAISO, 2016).

La adaptación al poder o las convenciones y la identificación con la dureza, el dinero, el rendimiento o el poder, que en realidad son imposiciones de la sociedad, se convierten en determinantes del yo debilitado, que proyecta su odio hacia todos los que real o supuestamente se sustraen a esas imposiciones. Puesto que la rabia que produce el tener que someterse a los poderes sociales opresores no puede dirigirse contra 
ellos, el yo debilitado acaba desviándolos contra sí mismo o proyectándolos hacia algo exterior más débil. Bajo estas condiciones es como si la economía libidinal exigiese un chivo expiatorio. Estamos ante un carácter dependiente y no integrado que reacciona hacia los más fuertes con sumisión y hacia los más débiles con desprecio.

Esta limitación esquemática de la percepción y la conciencia va frecuentemente unida al mecanismo de la proyección que está a la base de los prejuicios. Sobre otras personas o sobre grupos socialmente señalados son proyectados los propios deseos reprimidos, las debilidades no aceptadas y los aspectos desagradables de sí mismo. Esto puede dar paso a la agresión si ésta cuenta con cierta sanción social o es respaldada por el poder, lo que dado el caso permite una revaloración del yo débil a través de una gratificación narcisista por identificación con el propio colectivo y devaluación del grupo ajeno y, además, una descarga desbocada de las agresiones destructivas. El yo débil no es capaz de percibir el mundo en una forma que haga justicia a su complejidad y al carácter anónimo de sus estructuras, porque esa forma hiere el narcisismo individual y colectivo. Esto lleva a una personalización de las transformaciones que sufre el mundo económico, en realidad determinadas de modo abstracto.

La debilidad de yo y su repercusión en la constitución de los sujetos explica por qué el antisemitismo y la industria cultural, en cuanto mecanismos de integración regresiva, lo tienen tan fácil. Solo tienen que conectar con "los impulsos libidinales, los conflictos, las inclinaciones y las tendencias inconscientes” mediados por las relaciones sociales y, "en vez de hacerlos conscientes y de esclarecerlos” en relación con su constitución social, simplemente reforzarlas y manipulas (ADORNO, 1962, p. 366). Tanto el antisemitismo como la industria cultural actúan como "medios de masas”. Existe, pues, una conexión entre ambos. En sus análisis de la propaganda fascista, Adorno pone repetidamente de relieve que sus métodos y técnicas coinciden con los de la industria cultural: personificación, emocionalización, esterotipización, irracionalización (ADORNO, 1943). Los mecanismos de que se sirve han sido puestos en marcha por la cultura de masas moderna, la publicidad y la industria del entretenimiento. El antisemitismo es algo así como "la ontología del anuncio publicitario" (ADORNO, 1962, p. 367). De esta manera se tiene en cuenta la dimensión que adquiere en el antisemitismo las formas 
culturales de organización de la percepción específicas de la industria cultural (cf. CLAUSSEN 1987, 48, 52; 1992; 1994a; 1994b; 1995).

Pero si antisemitismo e industria cultural poseen una efectividad como "medios de masas", si los individuos se aferran a ellos a pesar de sus elementos irracionales, esto no puede entenderse si no se tiene en cuenta la función psicodinámica que cumplen para esos individuos en cuanto "falsas curaciones" (Schiefheilungen), que producen un alivio psíquico sin afrontar ni resolver los conflictos que originan frustración y malestar (MAISO, 2013, p. 144). La piscología social de orientación psicoanalítica recurre a dos conceptos no exentos de controversia para explicar dicha función psicodinámica.

\section{Carácter autoritario y narcisismo herido}

De acuerdo con su orientación terapéutica, el psicoanálisis es en principio una psicología individual volcada en la explicación y sanación de patologías individuales. Y para ello basta la consideración aislada de las constelaciones de la familia nuclear y de la socialización primaria. La constitución social de las condiciones de dicha socialización, empezando por la estructura patriarcal de la familia, quedan fuera del análisis y son naturalizadas. La crítica de la pseudo-naturaleza individual se produce a expensas de excluir de la crítica la pseudo-naturaleza social (DAHMER, 2013, p. 97). Por el contrario, la psicología social psicoanalítica, tal como cristaliza en la teoría crítica de la sociedad, tiene como objetivo dar cuenta de fenómenos colectivos, de estructuras de carácter específicamente sociales y entiende la familia como una agencia psicológica de la sociedad. Inicialmente el concepto de carácter social es concebido como una categoría estructural de actitudes que sirven de base al comportamiento de individuos y grupos, por lo general inconsciente y cargada libidinalmente. Su función en una sociedad antagonista consiste en canalizar energías libidinales de un modo que resulta funcional al sistema, contribuyendo a estabilizar las estructuras sociales coactivas. Las insatisfacciones y agresiones quedan reprimidas o son externalizadas de un modo compatible con la dominación.

Casi no es necesario decir aquí que la caracterología social ha sido sometida a una larga discusión y crítica. Sobre todo, por proceder subsumiendo la singularidad e individualidad. Pero lo que la 
caracterología crítica pretende es más bien reflexionar críticamente sobre un proceso de subsunción que se produce en la realidad social. Ningún individuo queda completamente subsumido en un carácter social. Más bien se trata de describir aquellas características psicológicas que deberían exhibir los individuos que encajan bien en unas relaciones sociales determinadas. En todo caso, es preciso evitar el peligro de simplificación, esto es, de establecer una correspondencia esquemática entre los cambios en los modos de regulación del sistema capitalista (liberalismo, fordismo, postfordismo, ...) y un cambio histórico de las formas de subjetivad. Carácter es resultado de la dinámica libidinal, pero no constituye ninguna totalidad cerrada, fijada y no contradictoria. Nunca existen en forma pura. No se puede hablar de "viejos" o "nuevos" tipos de personalidad. Incluso el propio concepto de personalidad supone un logro dudoso.

Teniendo en cuenta todo esto, el carácter cuyo análisis resulta relevante en el proceso de transformación de las formaciones sociales capitalistas desde el modelo liberal clásico hacia un modelo post-liberal autoritario no podía ser otro que el "carácter autoritario". En él se registra ya la crisis del sujeto burgués que tiene un origen objetivo en la crisis sistémica que pone en peligro en precario equilibrio la independencia personal (responsabilidad en la propia autoconservación) y la dependencia objetiva del proceso de acumulación del capital sustraído a su responsabilidad individual. El conflicto entre la necesaria ocupación libidinal del propio yo para resistir en la cada vez más enconada lucha por la supervivencia y la experiencia de impotencia frente a cambios estructurales incomprensibles y escasamente influenciables se "resuelve" en el carácter autoritario gracias a la ambivalencia entre sometimiento y rebelión coagulada en el psiquismo de los que se aferran al orden existente. Dicho carácter les permite dar una salida al conflicto interior identificándose con el dominio encarnado en una figura personal y proyectando la agresión contra grupos identificados como más débiles. Partiendo del análisis freudiano, es posible explicar por qué el carácter autoritario tiene que dirigir la agresión contra grupos considerados extraños. Su debilidad le impide dirigirla contra las autoridades del propio grupo. El conflicto intrapsíquico se proyecta sobre la relación entre el propio grupo y los grupos declarados ajenos, lo que permite la descarga de la agresividad y la identificación con la autoridad. El resultado es una 
paradójica "rebelión conformista": una especie de combinación entre el placer de obedecer y la agresión contra los indefensos.

También encontramos la misma necesidad de identificación con la autoridad o con el colectivo en el "narcisismo herido", que no es simplemente una figura históricamente posterior al carácter autoritario. $\mathrm{Su}$ clave está igualmente en el conflicto entre la necesidad de una ocupación libidinal de la propia persona y el agravio permanente que las condiciones sociales para asegurar la autoconservación infringen a los individuos. Dichas condiciones son percibidas como ajenas, extrañas o destinales y, al mismo tiempo, como precarias, cuando no asociadas a insuficiencias de los propios sujetos amenazados, pero raramente identificadas como resultado de coacciones sistémicas. Si las exigencias de autoconservación reclaman una ocupación libidinal adicional de la propia persona (narcisismo), la incapacidad de controlar las condiciones de existencia provoca un agravio permanente que abre y reabre la herida narcisista, cuya base objetiva es la impotencia real (ADORNO, 1955, p.72). La solución a este conflicto se produce a través de la colectivización del yo gracias a la identificación compartida. El narcisismo dañado encuentra cumplimiento en al narcisismo colectivo.

Las personas a las que se dirige [el caudillo] generalmente experimentan el conflicto moderno entre la instancia del yo organizada de manera racional y orientada a la supervivencia y la incapacidad continuada de satisfacer las demandas del propio yo (ADORNO, 1951B, P. 419).

Es necesario subrayar que estamos ante un conflicto estructural y duradero, característico del modo de producción capitalista y que se actualiza en formas nuevas de narcisismo colectivo. La solución de la herida narcisista en el narcisismo colectivo viene exigida, en cierto modo, por el sistema. La ofuscación que le es propia consiste en contribuir a que los sujetos interpreten su debilidad como fuerza (del colectivo), lo que no hace más que aumentar su debilidad.

\section{Límites del sujeto neurótico y el modelo edípico}

Una de las cuestiones más controvertidas en relación con las aportaciones de la teoría crítica sobre el carácter autoritario y el narcisismo herido es la tesis que vincula la evolución de la sociedad 
capitalista hacia formas monopolistas de economía y burocráticas de organización social y el debilitamiento de la figura paterna que presidía la pequeña familia patriarcal y sobre la que pivotaba hasta entonces el mecanismo de identificación en la socialización temprana. La consecuencia de este cambio, sobre el que se centran las primeras investigaciones psicosociales de la Teoría Crítica, es la no interiorización de la norma social en el superyó, que permanece exterior al individuo por la debilidad de la figura mediadora: el padre (cf. ADORNO et al., 1950, p. 201). En la actualidad la sociedad misma se presenta como el superyó. Con esta última consideración podría parecer que Adorno critica una falta de equilibrio entre las distintas instancias -ello, yo y superyó- y sus pretensiones, así como la incapacidad de mediación y sublimación, es decir, de desplazamiento o 'ennoblecimiento' de los impulsos libidinales, tal como plantea Freud. Con ello estaría asumiendo como ideal un 'yo integrado' que tiene su base en la solución exitosa del complejo de Edipo, es decir, en la internalización del superyó que da origen a la conciencia y a los sentimientos de culpa, pero que promete una regulación autónoma.

Jessica Benjamin ha criticado desde la perspectiva feminista que Adorno y Horkheimer se mantengan fieles al modelo edípico, según el cual la interiorización de la autoridad paterna es al mismo tiempo la condición de posibilidad de la autonomía (cf. BENJAMIN, 1982; BENJAMIN, 1993, p. 53-56 y 155-171). Desde su punto de vista la incoherencia se produce entre el modelo psicosocial de explicación de la debilidad del yo y la crítica de la dialéctica de la civilización como internalización del dominio. En el primero se responsabilizaría de la debilitación del yo a la debilitación de la figura paterna en la nueva situación del capitalismo autoritario, debilitación que estaría impidiendo una solución adecuada del problema edípico. El individuo integrado, es decir, aquel que ha conseguido una interiorización de la autoridad paterna y por medio de ello ha logrado constituir su conciencia como instancia autónoma, es el que está en condiciones de ofrecer resistencia a las exigencias de autoridades externas. Con ello se convierte a la internalización de la autoridad en base de la autonomía y la autoconciencia de yo.

Pero es precisamente esa internalización de la dominación lo que se convierte en objeto de la crítica de la civilización como introversión del sacrificio que encontramos, por ejemplo, en la Dialéctica de la Ilustración. Según J. Benjamin, esta paradoja pone de manifiesto que en el teorema de 
la debilitación del yo Adorno y Horkheimer quedan apresados en el modelo criticado por ellos mismos de la dolorosa interiorización del dominio y su transformación en una conciencia basada en la exclusión de lo difuso, de lo pulsional, de lo $>$ otro $=$. J. Benjamin crítica además el modelo edípico en sí mismo, ya que no es neutral desde un punto de vista de género. En el amor identificador edípico el padre es idealizado y la madre devaluada. El padre, como representante del mundo exterior, personifica la autonomía. Dado que la niña no es reconocida con el mismo valor que el niño, en la fase edipal se reproduce la forma más radical de desvalorización de la feminidad. A la niña se le niega la deseada autonomía a través de la identificación con el padre. Por el contrario, la teoría intersubjetiva de la personalidad que defiende J. Benjamin ve en el proceso de reconocimiento mutuo entre madre y niño/a en la fase más temprana de su evolución la condición de posibilidad para la consolidación de la subjetividad. El modelo interaccional sustentado en las relaciones tempranas entre la madre y el niño/a prevé un "equilibrio paradójico entre el reconocimiento y la autoconservación” (BENJAMIN, 1993, p. 48).

La cuestión que conviene dilucidar es si Adorno, apoyado en el modelo edípico, pretende defender la sociedad burguesa temprana frente a la tardía o si más bien pretende explicar el vuelco dialéctico de la una en la otra. Resaltar las diferencias entre una autonomía relativa encadenada, sin embargo, a las instancias que llevan a cabo desde el inicio su disolución, por un lado, y una pérdida casi completa de la autonomía por medio de una poderosa integración de los individuos en el capitalismo tardío, por otro, no significa que se convierta en ideal el primer término de la comparación. En la estructura patriarcal de la sociedad burguesa se encuentra inscrita la dinámica que, bajo la presión directa al conformismo, lleva a la disolución de una autonomía subjetiva que siempre fue ilusión en el capitalismo, pero no solo ilusión. La formación de la autonomía relativa en la fase temprana de sociedad burguesa gana su valor comparativo sólo en relación con la completa destrucción de esa autonomía relativa, pero no se convierte por ello en único modelo posible y, menos aún, deseable de formación de la autonomía. Si esto es así, Adorno no defiende un modelo patriarcal de sociedad, sino que diagnostica su descomposición, sin que la alternativa de una subjetividad emancipada aparezca a la vista. 
El modelo freudiano de explicación de la constitución del yo adquiere bajo la perspectiva de la Teoría Crítica un carácter histórico social. El ideal de Freud no es sólo la persona consciente que a través de un proceso doloroso no exento de represiones se convierte en dueño del ello. También es el varón creador de cultura, negador de los impulsos libidinales, desligado de los vínculos (con la madre) y sublimador. El superyó, que es interiorizado y entroncado a través de ese proceso y gracias a esa relación con la autoridad, en el sentido de volcar hacia dentro la agresión de carácter masoquista, juega un papel fundamental en el desarrollo del yo. Éste resulta tan contradictorio y ambivalente como la subjetividad burguesa en cuanto tal, pues es portador de una dimensión represiva y otra emancipadora. El proceso de la interiorización del superyó y de la identificación con el padre es para cada sujeto un proceso de sufrimiento que genera el yo, pero que también lo endurece y conforma sado-masoquistamente: el sujeto se convierte en su propia instancia disciplinadora. Este sujeto masculino, en cuanto sujeto patriarcal volcado a la consecución de objetivos y agente de la barbarie, se encuentra en el centro de la crítica de Adorno: la autonomía en su forma burguesa sólo es pensable al precio del distanciamiento y el dominio frente a la naturaleza propia y exterior, así como frente a otros sujetos. Incluso los objetivos eróticos, las necesidades pulsionales del Eros, están fundidos con la violencia, el sometimiento y las fantasías de poder referidas al propio yo y a los otros. Los elementos sado-masoquistas son parte de la interiorización psicosocial de la autoridad y la violencia represivas, de la conformación histórica del yo y la conciencia, y pertenecen al proceso de constitución de la autonomía y el sujeto burgueses. Lo importante desde el punto de vista de Adorno es no convertir estas tensiones son parte constitutiva de la génesis del sujeto en invariantes psíquicas o en "determinaciones antropológicas" (ADORNO, 1955, p. 61).

\section{Apuntes para una actualización}

El carácter histórico de la socialización y la constitución de la individualidad se hace especialmente patente, como hemos visto, en la tesis de la destrucción del sustrato psíquico del individuo a la que apunta el análisis de los procesos de debilitamiento del yo en el capitalismo monopolista de corte autoritario. El triunfo del fascismo ya refleja una 
atomización social y una desindividualización que cuestiona la prolongación del análisis freudiano. En este horizonte la teoría de Freud aparece como "el último gran teorema de la autocrítica burguesa" (ADORNO, 1951a, p. 67). A la vista de Auschwitz: un momento más de la Dialéctica de la Ilustración. El proceso histórico exige, según Adorno, transitar de la exploración de la mediación entre la universalidad social abstracta y la economía psíquico libidinal del individuo a la explicación de la anulación de las agencias mediadoras y sus consecuencias regresivas y desubjetivadoras en los individuos. Aquí es donde encaja la afirmación de Adorno de que "el mundo pre-burgués todavía no conoce la psicología, el mundo totalmente socializado ya no la conoce" (ADORNO, 1955, p. 82). ¿Queda suspendida la aportación del psicoanálisis? Para responder a esta pregunta no conviene olvidar que Adorno se refiere "al concepto liberal e individualista de psicología” (p. 82) y no está claro se refiera al psicoanálisis y a todo lo que el psicoanálisis aporta. En realidad, el envejecimiento de psicoanálisis, por usar una expresión de H. Marcuse (1963), se convierte, en un índice de las nuevas formas en que cristaliza la interiorización de la dominación social. O, como señala Adorno, el "psicoanálisis, en su figura auténtica e históricamente ya superada, adquiere su verdad en cuanto informe sobre los poderes de destrucción que bullen en el individuo en medio de la universalidad destructiva" (p. 83).

A este respecto, el concepto de "mundo administrado" pretende dar cuenta de una densificación de la tupida red de estructuras económicas, burocrático-administrativas y políticas, para las que la autonomía relativa del yo se convierte en un factor distorsionante que debe ser neutralizado, incluso y sobre todo allí donde es aparentemente exaltado y celebrado, como veremos. Esta situación lleva a formulaciones paradójicas como la de "carácter sin carácter" o "disolución del carácter". Lo que se expresa aquí es ciertamente la obsolescencia de tipos de carácter rígidos e inflexibles, que resultan ser disfuncionales. En su "Glosa sobre personalidad" (1966c), Adorno describe el derrumbe de este tipo de carácter congruente con una etapa de la socialización capitalista que ha perdido en el capitalismo tardío su función, sin que su derrumbe haya supuesto otro tipo de individualidad que merezca ese nombre. Sin embargo, la consideración de las nuevas formas de subjetivación como constitución de un manojo de reflejos parece perder de vista aquello que 
constituía unas de las más importantes aportaciones de la crítica de la industria cultural: la pseudo-individualidad. Los rituales de la cultura de masas simulan la individualidad que ellos mismos ayudan a sofocar. La espontaneidad que haría posible la constitución de la individualidad es eliminada al mismo tiempo que se simula su existencia (KÖNIG, 200o, p. 19). Aunque el "trabajo de Sísifo de la economía libidinal individual, hoy 'socializada', está gobernada por las instituciones de la industria cultural” (ADORNO, 1953, p. 508), esto no solo resulta completamente compatible con la simulación de la individualidad, sino que se sirve directamente de ella, la necesita para para hacer efectivo dicho gobierno. Lo cual apunta, según mi parecer, a posibilidad de actualización de la tesis del narcisismo herido en una nueva constelación entre las formas actuales de socialización capitalista y su interiorización, en la que es posible rastrear cómo bullen en los individuos los poderes de destrucción en medio de la universalidad destructiva: justo en la experiencia de sufrimiento socialmente producido.

Siguiendo esta argumentación, la teoría psicosocial del narcisismo herido puede conectarse sin dificultad con los nuevos diagnósticos de sociología del trabajo (EICHLER, 2012, 73ss., ZAMORA, 2013, 163ss.). Uno de los cambios más relevantes que se produce en el último tercio del siglo XX es la suspensión, cuando menos parcial, de la separación entre el uso de la mercancía "fuerza de trabajo" y la persona que es su portadora. En la nueva organización del trabajo, la persona misma es cooptada e incorporada al proceso productivo. Debido a los cambios en esa organización, la subjetividad deja de ser un "factor distorsionante" como en el taylorismo clásico para convertirse en un factor central de producción. Esto pasa por responsabilizar al trabajador asalariado de los resultados y, por tanto, del funcionamiento del proceso de producción, lo que le convierte en "sujeto" que ha de "dirigir" dicho proceso. Un signo de esta activación del sujeto es la significación que adquieren sus potenciales subjetivos y sus capacidades no sólo laborales (relacionales, sentimentales, afectivas, motivacionales, comunicativas, etc.). La totalidad de la persona con todo lo que constituye su vida personal adquiere nueva relevancia en el funcionamiento de la empresa. Existe un considerable consenso en la sociología del trabajo sobre el papel clave que juegan el sujeto y la subjetividad en la renegociación de la forma hegemónica de organización del trabajo en el postfordismo (MOLDASCHL - VOß, 2003). La fuerza de 
trabajo empresarizada se ha visto obligada a una responsabilización coactiva, mientras se mantenía una rígida dependencia insorteable respecto al marco de condiciones al que dicha responsabilidad se enfrenta. Se trata de una funcionalización o instrumentalización de la autonomía para reforzar la dependencia. Dado que las estructuras internas empresariales se ven forzadas a una permanente reorganización en función de las dinámicas y las contingencias de los mercados, se termina imponiendo una nueva forma de gestión empresarial: el gobierno indirecto. Se trata de una "forma de heterodeterminación de la acción que se implementa mediada a través de su propio opuesto, esto es, de la autodeterminación y la autonomía de los individuos, y por cierto de tal manera que puede prescindir de instrucciones explícitas, o incluso implícitas, así como de las amenazas de sanciones” (PETER y SAUER, 2006, p. 98).

Emerge así una nueva pseudo-individualidad que no deja de ampliar su radio de acción: el "yo empresario" (BRÖCKLING 2007). Se trata de una individualidad cuya sustancia es el sometimiento, pero las relaciones de poder ya no se articulan mediante estrategias de dominación desde fuera, sino mediante la activación de los potenciales de autocontrol de los individuos. Resulta evidente que muchos individuos tienen enormes dificultades para adaptarse "exitosamente" a las exigencias a las que intenta ser una respuesta adaptativa el carácter flexible. Muchos se sienten sobrepasados y desbordados por la coacción a una permanente autooptimización, lo que parece ser origen de múltiples psicopatologías o comportamientos autodestructivos. La exigencia de "ser uno mismo" y de contemplarse como una máquina de capitalización ilimitada es puesta en relación con la expansión de la depresión (EHRENBERG, 2000). La movilización neoliberal del yo sería la base de las condiciones de agotamiento y extenuación que son características de la depresión. Un ejemplo recurrente que parece avalar esta tesis es el síndrome cada vez más frecuente de burnout (fundido, agotado, quemado). La interiorización de una responsabilidad frente a la propia autorrealización y la propia felicidad en un horizonte cargado de peligros de fracaso, sin que este pueda descargarse sobre instancias externas, es la fuente de estrés específico y de la experiencia de verse desbordado. "La identidad de sociedad e individuo en la forma en la que se está abriendo paso es lo completamente negativo: 
así la experimenta el individuo, a través de un exceso de dolo físico y sufrimiento psíquico" (ADORNO, 1966b, p. 91).

La neurosis que se gestaba en la sociedad disciplinaria en torno al conflicto entre el deseo de trasgresión de la norma y el miedo al castigo ha dejado paso el cuadro depresivo del capitalismo post-disciplinario. La crisis crónica del yo tiene su origen en una desmesurada responsabilización de sí y una exigencia desbordada de autenticidad e individualidad. Por un lado, se alimenta la ficción de un yo soberano y por otro se minan las posibilidades de su realización. Precisamente esta es la base objetiva del modelo narcisista analizado por Adorno. Sin embargo, ahora el sufrimiento no nace del conflicto interno mediado por la coacción objetiva, sino de la completa adaptación a lo dado exigida por esa coacción bajo la forma de pseudoindividualidad. Se constata el fracaso del intento de desentrañar en las historias de vida de los individuos la prueba de la dinámica social, pero se recupera su fracaso como signo de la escisión entre sociedad e individuos, que marca a estos con un sufrimiento extremo: "La psicología se vuelve relevante no solo como medio de adaptación, sino también allí donde la constitución social encuentra su límite en el sujeto.” (ADORNO, 1966b, p. 92). La idea de una subjetividad lograda y armónica en medio de una sociedad antagónica no puede ser una clave de humanidad. Pero el sufrimiento que produce la subjetivación coactiva es la muestra de que la captura total no ha sido lograda.

\section{Bibliografía}

ADORNO, Theodor W. Reflexionen zur Klassentheorie. 1942a. In: Gesammelte Schriften (Vol. 8). R. TIEDEMAN (ed.). Frankfurt a.M.: Suhrkamp, p. 373-391.

ADORNO, Theodor W. George und Hofmannsthal. Zum Briefwechsel: 1891-19o6. 1942b. In: Gesammelte Schriften (Vol. 10). R. TIEDEMAN (ed.). Frankfurt a.M.: Suhrkamp, p. 195-237.

ADORNO, Theodor W. Thesen über Bedürfnis. 1942c. In: Gesammelte Schriften (Vol. 8). R. TIEDEMAN (ed.). Frankfurt a.M.: Suhrkamp, p. 392-396.

ADORNO, Theodor W. The Psychological Technique of Martin Luther Thomas' Radio Addresses. 1943. In: Gesammelte Schriften (Vol. 9). R. TIEDEMAN (ed.). Frankfurt a.M.: Suhrkamp, p. 9-141. 
ADORNO, Theodor W. et al. The Authoritarian Psychology, vol. 1 of Studies in Prejudice, edited by Max Horkheimer and Samuel F. Flowerman. 1950. In: Gesammelte Schriften (Vol. 10). R. TIEDEMAN (ed.). Frankfurt a.M.: Suhrkamp, p. 144-509.

ADORNO, Theodor W. Minima Moralia. Reflexionen aus dem beschädigten Leben, 1951a. In: Gesammelte Schriften (Vol. 4). R. TIEDEMAN (ed.). Frankfurt a.M.: Suhrkamp.

ADORNO, Theodor W. Freudian Theory and the Pattern of Fascist Propaganda, 1951b. In: Gesammelte Schriften (Vol. 8). R. TIEDEMAN (ed.). Frankfurt a.M.: Suhrkamp, p. 408-433.

ADORNO, Theodor W. Die revidierte Psychoanalyse. 1952. In: Gesammelte Schriften (Vol. 8). R. TIEDEMAN (ed.). Frankfurt a.M.: Suhrkamp, p. 20-41.

ADORNO, Theodor W. Prolog zum Fernsehen. 1953. In: Gesammelte Schriften (Vol. 10). R. TIEDEMAN (ed.). Frankfurt a.M.: Suhrkamp, p. 507-516.

ADORNO, Theodor W. Zum Verhältnis von Soziologie und Psychologie. 1955. In: Gesammelte Schriften (Vol. 8). R. TIEDEMAN (ed.). Frankfurt a.M.: Suhrkamp, p. $42-85$.

ADORNO, Theodor W. Zur Bekämpfung des Antisemitismus heute. 1962. In: Gesammelte Schriften (Vol. 20). R. TIEDEMAN (ed.). Frankfurt a.M.: Suhrkamp, p. 360-383.

ADORNO, Theodor W. Drei Studien zu Hegel. 1963. In: Gesammelte Schriften (Vol. 5). R. TIEDEMAN (ed.). Frankfurt a.M.: Suhrkamp, p. 247-381.

ADORNO, Theodor W. Gesellschaft. 1965. In: Gesammelte Schriften (Vol. 8). R. TIEDEMAN (ed.). Frankfurt a.M.: Suhrkamp, p. 9-19.

ADORNO, Theodor W. Negative Dialektik. 1966a. R. TIEDEMAN (ed.). In: Gesammelte Schriften (Vol. 6). Frankfurt a.M.: Suhrkamp.

ADORNO, Theodor W. Postcriptum. 1966b. In: Gesammelte Schriften (Vol. 8). R. TIEDEMAN (ed.). Frankfurt a.M.: Suhrkamp, p. 86-92.

ADORNO, Theodor W. Glosse über Persönlichkeit. 1966c. In: Gesammelte Schriften (Vol. 10). R. TIEDEMAN (ed.). Frankfurt a.M.: Suhrkamp, p. 639-644.

ADORNO, Theodor W. Spätkapitalismus oder Industriegesellschaft? 1968. In: Gesammelte Schriften (Vol. 8). R. TIEDEMAN (ed.). Frankfurt a.M.: Suhrkamp, p. 354-370.

ADORNO, Theodor W. Marginalien zur Theorie und Praxis. 1969a. R. TIEDEMAN (ed.). In: Gesammelte Schriften (Vol. 10). Frankfurt a.M.: Suhrkamp, p. 759-762.

ADORNO, Theodor W. Einleitung zum "Positivismusstreit in der deutschen Soziologie". 1969b. In: Gesammelte Schriften (Vol. 8). R. TIEDEMAN (ed.). Frankfurt a.M.: Suhrkamp, p. 280-353. 
1026 | Veritas | Porto Alegre, v. 63, n. 3, set.-dez. 2018, p. 998-1028

ADORNO, Theodor W. Zur Lehre von der Geschichte und von der Freiheit. Frankfurt am Main: Suhrkamp, 2001.

ASBACH, Olaf. Kritische Gesellschaftstheorie und historische Praxis. Entwicklung der Kritischen Theorie bei Max Horkheimer 1930-1942/43. Frankfurt et al.: Peter Lang, 1997.

BENJAMIN, Jessica. Die Antinomien des patriarchalischen Denkens. Kritische Theorie und Psychoanalyse. In: W. BONSS - A. HONNETH (eds.). Sozialforschung als Kritik. Zum sozialwissenschaftlichen Potential der Kritischen Theorie. Frankfurt a.M.: Suhrkamp, 1982, p. 426-455.

BENJAMIN, Jessica. Die Fesseln der Liebe. Psychoanalyse, Feminismus und das Problem der Macht. Frankfurt a.M.: Suhrkamp, 1993.

CLAUSSEN, Detlev. Grenzen del Aufklärung. Die gesellschaftlice Genese des moderne Antisemitismus, Frankfurt a.M.: Fischer, 1987.

CLAUSSEN, Detlev. Die antisemitische Alltagsreligion. Hinweise für eine psychoanalytisch aufgeklärte Gesellschaftstheorie. In: W. BOHLEBER, J.S. KAFKA (eds.), Antisemitismus. Bielefeld: Aisthesis, 1992, p. 163-170.

CLAUSSEN, Detlev. Was ist Rassismus? Darmstadt: Wissenschaftliche Buchgesellschaft, 1994a.

CLAUSSEN, Detlev. Veränderte Vergangenheit. Vorbemerkungen zur Neuausgabe 1994. In: Grenzen del Aufklärung. Die gesellschaftlice Genese des moderne Antisemitismus, Frankfurt a.M.: Fischer, 1994b, p. 7-32.

CLAUSSEN, Detlev. Konformistische Identität. Zur Rolle der Sozialpsychologie in der Kritischen Theorie. In: G. SCHWEPPENHÄUSER. Soziologie im Spätkapitalismus. Darmstadt: WBG, 1995, 27-40.

DAHMER, Helmut. Pseudonatur und Kritik. Freud, Marx und die Gegenwart. Frankfurt a.M.: Suhrkamp, 1994 .

DAHMER, Helmut. Libido und Gesellschaft. Studien über Freud und die Freudsche Linke. $3^{\mathrm{a}}$ ed. Münster: Westf. Daampfboot, 2013

DEMIROVIĆ, Alex. Der nonkonformistische Intellektuelle. Die Entwicklung der Kritischen Theorie zur Frankfurter Schule. Frankfurt am Main: Suhrkamp, 1999.

DUBIEL, Helmut. Wissenschaftsorganisation und politische Erfahrung. Studien zur frühen Kritischen Theorie, Frankfurt: Suhrkamp, 1978.

EICHLER, Lutz. Soziologie und Sozialpsychologie subjetktiver Arbeit. Psychosozial, $\mathrm{n}^{\mathrm{0}}$ 129, 2012, p. 71-84. 
EHRENBERG, Alain. La fatiga de ser uno mismo. Depresión y Sociedad. Buenos Aires: Ediciones Nueva, 2000.

FREUD, Sigmund. Selbstdarstellung. 1925. In: Werkausgabe - Gesammelte Werke in achtzehn Bänden mit einem Nachtragsband, Vol. XIV. Frankfurt a. M.: Fischer, 3196.

FREUD, Sigmund. Vorlesungen zur Einführung in die Psychoanalyse. 1916-17. In: Werkausgabe - Gesammelte Werke in achtzehn Bänden mit einem Nachtragsband, Vol. XI, p. 1-497.

FROMM, Erich. Über Methode und Aufgabe einer analytischen Sozialpsychologie. Bemerkungen über Psychoanalyse und historischen Materialismus (1932), In: ID. Gesamtausgabe in 10 Bänden, ed. por R. Funk, Stuttgart: Deutsche Verlagsanstalt, 1980/81, p. 37-57.

HORKHEIMER, Max. Geschichte und Psychologie. 1932. In: Gesammelte Schriften (Vol. 3). G. Schmid-Noerr (ed.). Frankfurt a. M.: Fischer, 1985ss., p. 48-69.

HORKHEIMER, Max. Autoritärer Staat. 1941. In: Gesammelte Schriften (Vol. 5). G. SchmidNoerr (ed.). Frankfurt a. M.: Fischer, p. 293-319.

HORKHEIMER, Max. Nachgelassene Schriften 1931-1943. In: Gesammelte Schriften (Vol. 12). G. Schmid-Noerr (ed.). Frankfurt a. M.: Fischer, 1985.

HORKHEIMER, Max et all. Wirtschaft, Recht und Staat im Nationalsozialismus. Analysen des Instituts für Sozialforschung 1939-1942. H. DUBIEL y A. SÖLLNER (eds.), Frankfurt: Europ. Vlg.-Anst., 1981.

JAY, Martin. The Dialectical Imagination: A History of the Frankfurt School and the Institute of Social Research, 1923-1950. Toronto: Little, Brown and Company, 1973.

JOHANNES, Rolf. Das ausgesparte Zentrum. Adornos Verhältnis zur Ökonomie. In: G. SCHWEPPENHÄUSER (ed.). Soziologie im Spätkapitalismus. Zur Gesellschaftstheorie Theodor W. Adornos, Darmstadt: WBG, 1995, p. 41-67.

KIRCHHOFF, Christine. Das psychoanalytische Konzept der "Nachträglichkeit”. Zeit, Bedetung und die Anfänge des Psychischen. Gießen: Psychosozial-Verlag, 2009.

KIRCHHOFF, Christine. Wozu noch Metapsychologie. Journal für Psychologie. 18/1, 2010.

KIRCHHOFF, Christine. Anpassung und Unvernunft. Die Bedeutung der Lebensnot bei Freud und Adorno. In: Kirchhoff, Christine \& Schmieder, Falko (eds.). Adorno und Freud. Zur Urgeschichte der Moderne, Berlin, Kadmos, 2014, p. 51-62.

KÖNIG, Hans-Dieter. Adornos psychoanalytische Kulturkritik und die Tiefenhermeneutik. Zugleich eine Sekundäranalyse des 24. Aphorismus der Minima Moralia. Zeitschrift für kritische Theorie, $\mathrm{n}^{\mathrm{0}}$ 10, 2000, p. 7-26. 
1028 | Veritas | Porto Alegre, v. 63, n. 3, set.-dez. 2018, p. 998-1028

KÜPPER, Christian. 'Psychologie reicht ans Grauen nicht heran' - Adorno zu Individuum und Gesellschaft. Forum Kritische Psychologie, 53, 2009, p. 119-135.

MAISO, Jordi. La subjetividad dañada: Teoría Crítica y psicoanálisis. Constelaciones. Revisa de Teoría Crítica, $\mathrm{n}^{\mathrm{o}}$ 5, 2013, p. 132-150.

MAISO, Jordi. Sobre la producción y reproducción social de la frialdad. In: J. A. ZAMORA, R. MATE, J. MAISO (eds.), Las víctimas como precio necesario. Madrid: Trotta, 2016, p. 51-69.

MARCUSE, Herbert. Das Veralten der Psychoanalyse. 1963. In: Kultur und Gesellschaft, vol. 2, Frankfurt a.M, Suhrkamp, 1968, p. 85-106.

MEYER, Lars. Absoluter Wert und allgemeiner Wille. Zur Selbstbegründung dialektischer Gesellschaftstheorie, Bielefeld: transcript, 2005.

PETER, Klaus - SAUER, Dieter. Epochenbruch und Herrschaft: indirekte Steuerung und die Dialektik des Übergang. In: D. SCHOLZ et all. (ed.). Turnaround? Strategien für eine neue Politik der Arbeit -Herausforderungen an Gewerkschaften und Wissenschaft, Münster: Westfälisches Dampfboot, 2006, p. 98-125.

POLLOCK, Friedrich. Bemerkungen zur Wirtschaftskrise. Zeitschrift für Sozialforschung, 1933, vol. 2/3, p. 321-354.

POLLOCK, Friedrich. State Capitalism: Its Possibilities and Limitations. Studies in Philosophy and Social Science, vol. 9/1, 1941, p. 200-225.

REICHE, Reime. Triebschicksal der Gesellschaft. Über Strukturwandel der Psyche. Frankfurt a.M./New York: Campus, 2004.

SCHILLER, Hans-Ernst. Freud-Kritik von links. Bloch, Fromm, Adorno, Horkheimer, Marcuse. Lüneburg: zu Klampen, 2017.

SCHMID NOER, Gunzelin. Zwischen Sozialpsychologie und Ethik - Erich Fromm und die "Frankfurter Schule". Psyche. Vol. 55, 2001, p. 803-834.

SCHNEIDER, Christian. Die Wunde Freud. In: Adorno Handbuch. Leben - Werk - Wirkung, ed. RICHARD, R. et al. Stuttgart: J. B. Metzler, 2011, p. 283-295.

WIGGERSHAUS, Rolf. Die Frankfurter Schule. Geschichte, Theoretische Entwicklung, Politische Bedeutung. München: DTV, 1988.

ZAMORA, José A. Subjetivación del trabajo: dominación capitalista y sufrimiento. Constelaciones. Revista de Teoría Crítica, Vol. 5, 2013, p. 151-169. 